\title{
Capítulo 3 TIPIFICACIÓN DE ACTORES SOCIALES EN LA SELECCIÓN DE DOCUMENTOS
}

Estos énfasis definidos aquí analíticamente se encuentran sustentados por diferentes actores sociales que tienen mayor o menor nivel de certeza política respecto al énfasis por seguir. La indagación realizada hasta el momento permite visualizar cuatro tipos de actores sociales relevantes para el estudio del pensamiento latinoamericano respecto del objeto de investigación, en cuanto desarrollaron un pensamiento sistemático rastreable e incidieron en procesos y corrientes sociales que pusieron a prueba sus opciones teóricas. Estos tipos de actores pueden ser caracterizados de la siguiente forma:

1. Aquellos que en torno a instituciones relacionadas con la planificación del desarrollo lograron hacer desarrollos teóricos alternativos, en especial en el campo económico-social. Entre las personalidades que podemos involucrar para hacer seguimiento al pensamiento desarrollado desde esta perspectiva están el argentino Raúl Prebish (1901-1986)²; el alemán André Gunder Frank (19292005); los brasileros Fernando Henrique Cardoso (1931-), Celso Furtado

2 Economista argentino. Fue el primer secretario general de la Cepal y posteriormente de la Comisión de las Naciones Unidas para la Conferencia de las Naciones Unidas sobre Comercio y Desarrollo (UNCTAD). 
(1920-2004) $)^{3}$, Theotonio dos Santos (1936-) y João Bosco Pinto (1939-); el chileno Enzo Faleto (1935-2003); el italiano radicado en argentina Gino Germani (1911-1979); Jorge Marquez Vaz; y la chilena radicada en México Vania Bambirra. En los años ochenta es interesante ver la continuidad del análisis que hace Immanuel Wallerstein a la teoría de la dependencia en la línea de André Gunder Frank. Como institución, es de especial atención el papel de la Cepal.

2. Aquellos que centraron su actuar político en incidir sobre la estructura social e involucraron la academia y la acción organizada. Desde la perspectiva del subdesarrollo, algunas personalidades que registran su producción académica y política en torno a la crítica del desarrollo son Paulo Freire desde la pedagogía del oprimido, Antonio García en torno al desarrollo agrario y Camilo Torres Restrepo con la reforma social y política de la sociedad. En el orden institucional es importante mirar la Universidad Nacional de Colombia, y se intuye un papel importante de la Universidad Nacional Autónoma de México, la Universidad Obrera de México y la Universidad Popular González Prada de Perú. Por otro lado, se reconoce las acciones del Frente Unido como partido político, dado el liderazgo de Camilo Torres Restrepo en este. En este orden, queda por examinar el papel de la filosofía de la liberación con personalidades como Enrique Dussel.

3. La Iglesia y su accionar institucional en el marco generado por el Concilio Vaticano II y su particular desarrollo alrededor de la teología de la liberación. Es resaltable el papel desempeñado por los documentos de la Segunda Conferencia General del Episcopado Latinoamericano, llevada a cabo en Medellín en 1968, y los aportes de los documentos fuente y desarrollos posteriores.

3 En 1958 y 1959 fue director del Banco Brasileño de Desarrollo Económico y Social, desde donde concibió y creó la Superintendencia para el Desarrollo del Nordeste (Sudene), una agencia gubernamental pionera para impulsar el desarrollo económico en el atrasado nordeste brasileño. Fue superintendente de esta agencia desde 1959 hasta 1964.

4 Entre los cargos administrativos que ha ocupado están los de director del Centro de Estudios SocioEconómicos de la Universidad de Chile (CESO); director en la División de Postgrado de Economía de la Universidad Nacional Autónoma de México y del Departamento de Doctorado del Seminario Permanente sobre Latinoamérica (México); formó parte del consejo directivo del programa de postgrado en Ciencia Ambiental de la Universidade Federal Fluminense, y fue secretario de Asuntos Internacionais do Governo do Estado de Rio de Janeiro. 
Igualmente, son importantes los aportes de Helder Câmara, Gustavo Gutiérrez, Juan Bosch y el padre francés dominico Joseph Lebret.

4. Finalmente, los movimientos guerrilleros de izquierda, dado que esta fue la época de consolidación de movimientos nacionales con una amplia circulación de ideas en el subcontinente, donde la preocupación por el desarrollo de los pueblos fue central. Muestra de ello son los desarrollos institucionales y extrainstitucionales mencionados en los puntos anteriores. Se podría dar una mirada a versiones institucionalizadas como la de la Revolución cubana, contrastada con miradas que se mantuvieron en la clandestinidad. 
